\title{
Acceptability of clinics for sexually transmitted diseases among users of the "gay scene" in the West Midlands
}

Vivian D Hope, Christine MacArthur

Objectives: To examine the acceptability of genitourinary medicine (GUM) clinics (for STDs) to homosexual and bisexual men.

Design: A cross sectional survey of men using "gay" venues and groups in the West Midlands region of the UK. Data were collected using an anonymous self-completed questionnaire.

Results: 848 completed questionnaires were returned. Two thirds of the respondents reported "safer" sexual behaviour. Those who had ever attended a GUM clinic (55\%) differed little in their safer sexual behaviour from those who had never attended. The acceptability of the service was assessed using a range of indicators: the majority of the attendees had told a doctor, nurse or health adviser they have sex with men; and just over half had found all staff to be friendly, helpful or not homophobic. A quarter of attendees found talking about sexual matters difficult; these were less likely to have found the service acceptable. Over half $(54 \%)$ of the study respondents had not been vaccinated against hepatitis B. Those who had been vaccinated were more likely: to have found the service acceptable; to have found talking about sexual matters easy; and to report safer sexual behaviour.

Conclusions: These findings suggest that many homosexual and bisexual men who may need to use the GUM service have not done so. There is a need to improve the acceptability of the service and to further promote hepatitis $\mathrm{B}$ vaccination.

(Genitourin Med 1997;73:299-302)

Keywords: STD, acceptability of clinics; hepatitis B; homosexual men; bisexual men

\section{Introduction}

Genitourinary medicine (GUM) clinics in the UK provide a free and confidential sexual health service. In general population surveys attendance at such clinics by men has been associated with, among other factors, having "one or more homosexual partners". ${ }^{\text {T The use }}$ of these clinics by men who have sex with other men probably reflects the confidentiality of the service and the reluctance of this group to be open about their sexuality with general practitioners, because of the disclosure of their sexuality to third parties, such as insurance companies, as well as their concerns about homophobia. ${ }^{2}$

GUM clinics are the main providers of services for the treatment and care of STDs, HIV testing and, for homosexual and bisexual men, of hepatitis B vaccination. If these clinics are to be effective in these roles and in the promotion of healthy sex, they need to be acceptable to all their users. ${ }^{34}$

In this paper we report a study of the acceptability of the GUM services, and the uptake of the hepatitis $B$ vaccine by men who use the "gay" scene in the West Midlands region of the UK.

\section{Methods}

Men recruited from a range of homosexual commercial and social settings were asked to self-complete an anonymous questionnaire. Information collected included demographic and lifestyle factors and details of sexual behaviour and condom use, as well as on use and experiences of GUM clinics. The questions had structured responses and the design was such that it could be easily completed in about 10 minutes.

The questionnaire was distributed with the support of a number of projects working with homosexual and bisexual men, who also had input into the questionnaire design. Four recruitment methods were used. Method one: the questionnaire was given directly to men using "gay" venues, who were asked to complete the questionnaire immediately and return it to a locked ballot box. All those attending during a given time were offered inclusion. This was the most common method of distribution and was used for all the bars and nightclubs. Method two: the questionnaire was given to men attending social groups, who were asked to complete the questionnaire and return it in a reply paid envelope. Method three: questionnaires were left in a prominent position in a sauna, with an explanation of the survey and a locked ballot box provided for their return. Method four: questionnaires were posted out as an enclosure with a newsletter, and a reply paid envelope provided for their return.

In bars and nightclubs 691 men were approached and 611 questionnaires were returned $(88.4 \%)$. The newsletter was sent to 201 men and 49 questionnaires were returned with a low response of $24 \cdot 4 \%$. There were a 
Table 1 Reported safer sex and GUM clinic attendance

\begin{tabular}{lll}
\hline \multirow{2}{*}{$\begin{array}{l}\text { When you have } \\
\text { sex with men is it } \\
\text { safer sex? }\end{array}$} & \multicolumn{2}{l}{ GUM clinic attendance (\%) } \\
\cline { 2 - 3 } & $\begin{array}{l}\text { Ever attended } \\
\text { GUM clinic }\end{array}$ & $\begin{array}{l}\text { Never attended } \\
\text { GUM clinic }\end{array}$ \\
\hline Always & $288(64 \cdot 1)$ & $232(65 \cdot 4)$ \\
Nearly always & $133(25 \cdot 2)$ & $61(17 \cdot 2)$ \\
Sometimes & $23(5 \cdot 1)$ & $34(9 \cdot 6)$ \\
Rarely & $6(1 \cdot 3)$ & $6(3 \cdot 4)$ \\
Never & $19(4 \cdot 2)$ & $19(4 \cdot 5)$ \\
Total & 499 & $355^{\mathrm{p}}=0.0044$ \\
\hline
\end{tabular}

further 119 returned from social groups and 79 from the sauna, but no response rates could be calculated for these because attendance was not reliably known. It is likely that some of those receiving the newsletter, attending the groups and using the sauna would have been approached and taken part elsewhere. In total 858 questionnaires were received.

Those recruited in the bars and nightclubs were compared with those recruited from other sources; no significant differences were found in age, ethnicity, employment status, social class or relationship status of the respondents.

Analysis was undertaken using sPsspct. Association was tested using the $\chi^{2}$ test unless otherwise indicated.

\section{Results \\ Sample characteristics \\ The sample contained men from across the West Midlands region; $49.7 \%$ were aged under $30,95 \cdot 8 \%$ were white and $70.3 \%$ were working. There were $44.5 \%$ who had non- manual occupations, $19.4 \%$ manual occupa- tions, $12 \cdot 9 \%$ were students and $23 \cdot 2 \%$ gave insufficient information to be classified. Just over half of the sample $(55 \cdot 1 \%, n=451)$ had ever attended a GUM clinic: $26 \%$ had last done so in the preceding year, $16.7 \%$ one to five years ago and $12 \cdot 3 \%$ over five years ago. Attendance had been at a number of GUM clinics across the UK, although $21 \cdot 7 \%$ had last attended one large clinic in the centre of Birmingham which is popular with homosex- ual and bisexual men.}

There were no differences between those

Table 2 Consistency of safer sex practice in the last 12 months and GUM clinic attendance

\begin{tabular}{|c|c|c|c|c|}
\hline \multirow[b]{3}{*}{$\begin{array}{l}\text { Consistency of safer sex } \\
\text { practice in the previous year }\end{array}$} & \multicolumn{3}{|c|}{ GUM clinic attendance (\%) } & \\
\hline & \multirow[b]{2}{*}{$\begin{array}{l}\text { Attended in } \\
\text { previous year }\end{array}$} & \multicolumn{2}{|c|}{$\begin{array}{l}\text { Not attended in } \\
\text { previous year }\end{array}$} & \\
\hline & & $\begin{array}{l}\text { Previously } \\
\text { attended over } \\
\text { a year ago }\end{array}$ & $\begin{array}{l}\text { Never } \\
\text { attended a } \\
\text { GUM clinic }\end{array}$ & \\
\hline $\begin{array}{l}\text { Anal sex in the last } 12 \text { months } \\
\text { Consistent condom use }\end{array}$ & $105(55 \cdot 5)$ & $106(55 \cdot 5)$ & $157(56 \cdot 1)$ & \\
\hline $\begin{array}{l}\text { Inconsistent condom use } \\
\text { with boyfriend only } \\
\text { Inconsistent condom use } \\
\text { with a partner type other } \\
\text { than boyfried or more } \\
\text { than one partner type }\end{array}$ & $36(19 \cdot 1)$ & $42(21 \cdot 9)$ & $50(17 \cdot 9)$ & \\
\hline $\begin{array}{l}\text { Total having anal sex in } \\
\text { last } 12 \text { months }\end{array}$ & 189 & 191 & 280 & NS \\
\hline No anal sex in last 12 months & $24(11 \cdot 3)$ & $47(19 \cdot 7)$ & $88(23 \cdot 9)$ & \\
\hline Total & 213 & 238 & 368 & ${ }^{\star} p=0.0010$ \\
\hline
\end{tabular}

${ }^{\star}$ Comparison of anal sex (irrespective of condom use) and no anal sex in the last 12 months. who had ever attended (attendees) and those who had never attended (non-attendees) a GUM clinic in ethnicity, employment status, social class or relationship status. Clinic attendees, however, were older than non-attendees (median age of 31 years (mean 32.3 ) compared with 27 years (mean 30.9), MannWhitney test $\mathrm{p}=0.0015$ ).

Sexual behaviour and GUM clinic attendance

The survey contained a number of questions about safer sexual behaviour. Firstly, the responses to the question "When you have sex with men is it safer sex?": $64 \cdot 1 \%$ of the attendees reported always; $25 \cdot 2 \%$ nearly always; $5 \cdot 1 \%$ sometimes; $1 \cdot 3 \%$ rarely; and $4 \cdot 2 \%$ never. The second was a consistency of safer sex practice "measure", based on the responses to in a series of questions about condom use for $\vec{\circ}$ anal sex with different partner types $\overrightarrow{\vec{H}}$ ("boyfriends"; other "regular" partners; and "casual" partners) in the last 12 months: on $64.6 \%$ of the attendees reported either always using condoms $(44.6 \%)$ or no anal sex $(20.0 \%) ; 15 \cdot 3 \%$ reported not always using condoms with "boyfriend" but consistent use with other partners; and $20.2 \%$ reported inconsistent condom use with a partner type other than "boyfriend" or inconsistent use with more than one partner type.

Attendee and non-attendee responses to these questions about safer sexual behaviour were compared. The responses to the question When you have sex with men is it safer sex? are given in table 1 . This shows that at the extreme ends, always and never practising safer sex, there were no differences between clinic attendees and non-attendees. For the intermediate responses, however, attendees were more likely to report that they nearly always practised safer sex, whereas non-attendees were more likely to say sometimes or rarely. When clinic attendance was examined in relation to the consistency of safer sex practice in the last 12 months, the only difference was that those who had attended a clinic in the previous year were more likely to have had 5 anal sex than those who had attended either more than a year ago or never attended (table 2). Among those who had anal sex in o the last 12 months, there were no differences $N$ in consistency of safer sex practice between recent, previous and never attendees.

\section{Acceptability of the GUM service}

A number of questions were included on the : acceptability of the GUM service and the attendees ability to talk about sexual matters with the clinic staff. Among those who had ever attended a GUM clinic $85.5 \%$ had told the doctor that they had sex with men, $74.6 \%$ had told a health adviser and $67.9 \%$ a nurse. Those who had attended were asked three further questions about acceptability: $58.3 \%$ reported feeling that "all" staff were friendly; $55.9 \%$ that "all" staff were helpful; although $31 \cdot 1 \%$ felt that some staff were homophobic (anti-gay). Attendees were also asked if they had found it difficult to talk about sexual matters, and $26 \cdot 1 \%$ said that they had. There were 
Table 3 Uptake of hepatitis B vaccination and employment status

\begin{tabular}{lcccc}
\hline & \multicolumn{2}{l}{ Employment status (\%) } & \\
\cline { 2 - 4 } Hepatitis B vaccination & Students & Working & Not working & \\
\hline Vaccinated & $28(25 \cdot 0)$ & $208(36 \cdot 7)$ & $39(31 \cdot 2)$ & \\
Being vaccinated & $19(17 \cdot 0)$ & $36(6 \cdot 3)$ & $10(8 \cdot 0)$ & \\
Not vaccinated & $64(57 \cdot 1)$ & $298(52 \cdot 6)$ & $68(54 \cdot 4)$ & \\
Had hepatitis B & $1(0 \cdot 9)$ & $25(4 \cdot 4)$ & $8(6 \cdot 4)$ & $\mathrm{p}=0.0012$ \\
Total & 112 & 567 & 125 & \\
\hline
\end{tabular}

no associations between any of the above indicators of clinic acceptability and age, ethnicity, employment status, social class or the two measures of safer sexual behaviour.

When those who found talking about sexual matters difficult were compared with those who had not, the former were found to be less likely to have told staff they had had sex with men: $77 \cdot 3 \%$ of those who found talking about sexual matters difficult had told a doctor, compared with $90 \cdot 1 \%$ of those who had not ( $p=0.0047$ ); and $60.5 \%$ had told the health adviser compared with $81 \cdot 0 \%(\mathrm{p}<0.0001)$. The attendees who found talking about sexual matters difficult were also less likely to have felt "all" staff to be friendly (25.0\% compared with $67.4 \%, \mathrm{p}<0.0001)$ and helpful $(21.8 \%$ compared with $65.3 \%, \mathrm{p}<0.0001$ ) and were more likely to think "some" or "most" of the staff were homophobic $(67 \cdot 2 \%$ compared with $17 \cdot 3 \%, \mathrm{p}<0.0001)$

\section{Uptake of hepatitis B vaccination}

The respondents were asked whether they had been vaccinated against hepatitis $B ; 33.9 \%$ had been, $8.9 \%$ were being vaccinated and $53.8 \%$ had not been vaccinated, the remainder $(4 \cdot 3 \%)$ having had hepatitis $B$. Uptake of vaccine was not associated with ethnicity or social class, but was associated with employment status (table 3). Students were less likely to have been vaccinated and more likely to be in the process of being vaccinated. Age was also associated with hepatitis $B$ vaccination, with those who were in the process of being vaccinated being younger (median age $24 \cdot 0$ years, mean age 26.6 ) than those who were either vaccinated (median 28, mean 30.4 ) or not vaccinated (median 31.0 , mean $32 \cdot 8$ ), while those who had had hepatitis $B$ were older (median 36.0, mean 37.1) (Kruskal-Wallis, $\mathrm{p}<0.0001)$.

Uptake of hepatitis B vaccination (having been vaccinated or being vaccinated) was found to be associated with clinic acceptability. Among those who had told a doctor they had sex with men, vaccination uptake was $60 \cdot 1 \%$ compared with $21 \cdot 6 \%$ for those who had not $(p=0.0001)$; uptake was $61.6 \%$ for those who had told the health adviser they had sex with men compared with $31.3 \%$ for those who had not $(p=0.0052)$; and uptake was $62 \cdot 6 \%$ for those not finding any of the staff to be homophobic compared with $45 \cdot 8 \%$ of those who reported at least some staff homophobic $(p=0.0077)$. No associations were found between hepatitis $B$ vaccination and whether the staff were reported to be friendly or helpful. Those not being vaccinated were more likely to report finding talking about sexual matters difficult $(10 \cdot 4 \%$ compared with $4 \cdot 8 \%, p=0 \cdot 0128)$.

The uptake of hepatitis $B$ vaccination was found to be associated with the practice of safer sex. Those who had been vaccinated or who were being vaccinated were more likely to have responded to "When you have sex with men is it safer sex?" with "always" or "nearly always" (92.0\% compared with $82.4 \%$, $p=0.0147)$. This group were also less likely to report inconsistent condom use in the previous 12 months with a partner type other than "boyfriend", or with more than one partner type $(17.0 \%$ compared with $22.0 \%$, $\mathrm{p}=0.0360)$.

\section{Discussion}

It would usually be supposed that attendees at GUM clinics are at greater risk of acquiring sexually transmitted diseases and HIV than non-attendees. The findings of this study, however, suggest that among homosexual and bisexual men this may not be the case. From questioning men using gay venues and social groups it appears that as many of those who have not attended a GUM clinic were as at risk of sexually acquired HIV infection as those who have attended such a clinic. Among those who have had sex in the last 12 months (the majority of the sample) the same proportion of non-attendees as attendees reported inconsistent condom use for anal sex. In addition, in response to a general question about practice of safer sex with men, although the proportions at the extremes (always and never practice safer sex) were the same, attendees were more likely to say they nearly always practised safer sex, whereas non-attendees were more likely to say sometimes or rarely.

In their detailed study of the sexual behaviour of homosexual and bisexual men recruited from community settings Project SIGMA $^{5}$ found that clinic attendees (those who attended often or had done so in the preceding year, $30.9 \%$ of their sample) had had anal sex with more partners than had nonattendees. SIGMA does not report on any other aspects of the sexual behaviour of attendees and non-attendees, other than that the HIV seroprevalence among the attendees was higher, probably reflecting the fact that many HIV antibody positive men get treatment from GUM clinics. Overall, however, SIGMA did not find a relation between condom use and the number of partners. The number of sexual partners was not ascertained in this present study so comparisons between the studies are not possible.

The present study also found that over half the men had not taken up hepatitis B vaccination, which homosexual and bisexual men in the UK usually obtain at GUM clinics. This is another indication that a large number of homosexual men who need to use the GUM service are not doing so.

Men may fail to use the GUM service for many reasons, such as not being able to access clinics or because the service provided is unac- 
ceptable. ${ }^{4}$ This study has shown that although the service was generally acceptable to those men who had used it, some still reported experiencing unfriendly, unhelpful or homophobic staff. The level of acceptability reported here by homosexual and bisexual men was lower than that found in a population of male and female attendees at five clinics in the West Midlands region of the UK. ${ }^{4}$ This disparity indicates, not surprisingly, that clinic based surveys give a more positive view of service acceptability, possibly reflecting a reluctance of attendees to be critical when questioned at the site of service provision.

In this present study about one quarter of the men who had attended a GUM clinic had found it difficult to talk about sexual matters. These men were less likely to report an acceptable service, to have told clinic staff they had sex with men and to have been vaccinated against hepatitis $B$. The GUM service needs to provide a comfortable and accepting environment which is appropriate to constructive discourses between staff and clients about sexual matters. The need for this environment to be free from prejudice is reiterated by the fact that men who found it difficult to talk about sexual matters were also much more likely to report homophobic staff. Some men of course might not feel able to talk freely about sexual matters however accepting and comfortable a clinic environment was. Clinics may need also to develop strategies to work with such individuals.

In recent years vaccination against hepatitis $B$ has been promoted for homosexual and bisexual men. In this study one third of the men had completed the hepatitis $B$ vaccine, a figure that is lower than the $41.7 \%$ reported in a 1991-2 study of men recruited from both GUM and community settings. ${ }^{6}$ There is therefore a continued need for the promotion of hepatitis B vaccination. Since many homosexual men have never, let alone recently, attended a GUM clinic, to be successful such a campaign will need to involve not only the GUM service but other health promoting agencies and gay community organisations.

Uptake of the hepatitis B vaccination pro- gramme was found to be related to consistent condom use. Hart et $a l^{6}$ had previously found that unvaccinated men who had been exposed to hepatitis B were more likely to report unsafe sex with casual partners and to report more lifetime STDs. These findings suggest that those who are most successful in their adoption of safer sex practice may also be those most likely to have adopted other health protective measures or most value themselves and their health. The sexual health of homosexual $\Phi$ and bisexual men may, therefore, be further improved by the development of strategies $\stackrel{\vec{S}}{\stackrel{7}{3}}$ that promote their broader health and wellbeing.

The findings of this study raise a number of $\frac{\overline{\bar{c}}}{\bar{D}}$ issues. Firstly, the GUM service needs to work $\stackrel{\mathbb{Q}}{\Omega}$ to improve its overall acceptability to homo- क sexual and bisexual men; the sexual practices $\vec{\circ}$ of non-attendees puts them at just as great a risk as attendees. Secondly, clinics need to $\vec{\omega}$ develop strategies to ensure that they provide a $\stackrel{\text { of }}{=}$ suitable environment for people to talk about sensitive sexual matters. Thirdly, together with other agencies, including statutory funded i⿱ Gay Men's Health Projects and voluntary organisations, they need to further promote 9 hepatitis B vaccination. Finally, these various activities will probably be most effective if conducted within a wider framework that actively $\frac{C}{\oplus}$ seeks to promote the well being of homosexual and bisexual men.

We thank all the men who took part in this study, those projects who provided assistance and the West Midlands Regional Health Authority Research and Development Directorate for funding this work.

1 Johnson AM, Wadsworth J, Wellings K, Field J. Sexual Attitudes and Lifestyles. London: Blackwell, 1994:279.

2 Fitzpatrick R, Dawson J, Boulton M, McLean J, Hart G, $\overrightarrow{\vec{D}}$ Brookes $M$. Perceptions of general practice among Brookes $M$. Perceptions of general practice
homosexual men. Br $\mathcal{f}$ Gen Pract 1994;44:80-2.

3 Jones J. Sexuality awareness for genitourinary medicine $?$ professionals. In: Pillaye J, ed. Sexual Health Promotion in Genitourinary Medicine Clinics. London: Health Education Authority, 1994.

4 Hope VD, MacArthur C. Accessibility of genitourinary medicine clinics. Genitourin Med 1996;72:52-5.

5 Davies PM, Hickson FCI, Weatherburn P, Hunt AJ. Sex, Gay Men and AIDS. London: The Falmer Press, 1993: 100.

6 Hart GJ, Dawson J, Fitzpatrick RM, Boulton M, McLean $\mathrm{J}$, Brookes M, et al. Risk behaviour, anti-HIV and anti- $\mathrm{O}$ ples of gay men in England 1991-1992. AIDS 1993;7: ples of gay men in England 1991-1992. AIDS 1993;7:
863-9. 